NBER WORKING PAPER SERIES

QUALITY COMPETITION VERSUS PRICE COMPETITION GOODS:
AN EMPIRICAL CLASSIFICATION

Richard E. Baldwin

Tadashi Ito

Working Paper 14305

http://www.nber.org/papers/w14305

\author{
NATIONAL BUREAU OF ECONOMIC RESEARCH \\ 1050 Massachusetts Avenue \\ Cambridge, MA 02138 \\ September 2008
}

The views expressed herein are those of the author(s) and do not necessarily reflect the views of the National Bureau of Economic Research.

NBER working papers are circulated for discussion and comment purposes. They have not been peerreviewed or been subject to the review by the NBER Board of Directors that accompanies official NBER publications.

(C) 2008 by Richard E. Baldwin and Tadashi Ito. All rights reserved. Short sections of text, not to exceed two paragraphs, may be quoted without explicit permission provided that full credit, including $\odot$ notice, is given to the source. 
Quality competition versus price competition goods: An empirical classification

Richard E. Baldwin and Tadashi Ito

NBER Working Paper No. 14305

September 2008, Revised October 2008

JEL No. F14

\begin{abstract}
$\underline{\text { ABSTRACT }}$
Based on the recent trade models of the Heterogeneous Firms Trade (HFT) model and the Quality Heterogeneous Firms Trade (QHFT) model, we classify export goods (at the HS 6-digit level of disaggregation) by quality and price competition. We find a high proportions of quality-competition goods for the major EU countries and lower proportions for Canada, Australia and China. However, the overlap of these quality-competition goods is not large, which suggests that characteristics of export goods are substantially different across countries at the same HS 6-digit code.
\end{abstract}

\author{
Richard E. Baldwin \\ Graduate Institute, Geneva \\ Cigale 2 \\ Lausanne Switzerland 1010 \\ and NBER \\ baldwin@graduateinstitute.ch \\ Tadashi Ito \\ Graduate Institute, Geneva \\ 11 a Ave de la Paix \\ Geneva 1202 \\ tadashi.ito@graduateinstitute.ch
}




\title{
Quality competition versus price competition goods: An empirical classification
}

\author{
Richard E. Baldwin and Tadashi Ito* \\ Graduate Institute of International and Development Studies, Geneva
}

\begin{abstract}
:
Based on the recent trade models of the Heterogeneous Firms Trade (HFT) model and the Quality Heterogeneous Firms Trade (QHFT) model, we classify export goods (at the HS 6-digit level of disaggregation) by quality and price competition. We find a high proportions of quality-competition goods for the major EU countries and lower proportions for Canada, Australia and China. However, the overlap of these quality-competition goods is not large, which suggests that characteristics of export goods are substantially different across countries at the same HS 6-digit code.
\end{abstract}

\section{Key words: Quality vs Price competition, heterogeneous firms trade model.}

\section{JEL Classification: F14}

\section{INTRODUCTION}

Recent work on the theory and empirics of firm heterogeneity and trade provides new and wide ranging insights. In the mainstay model in this 'new new trade theory' - the heterogeneous firms trade model of Melitz (2003) - competitiveness of a firm's product depends upon price; the cheapest goods are the most competitive. A minor twist on this model (which was foreshadowed by a footnote in Melitz 2003) turns the standard heterogeneous firms trade (HFT) model into the quality heterogeneous firms trade (QHFT) model where competitiveness depends upon the quality-adjusted price. If consumers care enough about quality, the highest priced goods are the most competitive, so the association between observed price and competitiveness is reversed, i.e. firms with the lowest observed prices are the least competitive. ${ }^{1}$

A simple empirical prediction separates the HFT and QHFT models in trade data. Since trade costs rise with distance of the market, the HFT model predicts that products with the lowest price get sold in the most distant markets while the opposite holds in the QHFT, i.e. the highest priced goods travel the furthest. These diametrically opposed implications provide the foundation of a test of the models by Baldwin and Harrigan (2006), BH henceforth; that paper, however, pools across all categories of US exports thus implicitly assuming that all US exports are characterised either by a falling price-distant link (HFT) or by a rising price-distant link (QHFT).

Our paper follows up on the BH by estimating the price-distance relationship separately for each product using panel data. Our paper's main value-added is to establish a list of three types of products. Those where competition appears to be based on price, those where it is based on quality, and those that cannot be confidently placed in either category. Specifically we use export data for nine large exporting nations at the HS 6-digit ${ }^{2}$ level of disaggregation. Our key findings are:

\footnotetext{
*11 Avenue de la Paix, 1202 Geneva, Switzerland; Baldwin@graduateinstitute.ch, Tadashi.Ito@graduateinstitute.ch.

${ }^{1}$ See Baldwin and Harrigan (2006).

${ }^{2}$ In the text below, the terms 'HS 6-digit' and 'HS6' are used interchangeably.
} 
1) Of the HS 6-digit codes that can be clearly classified as quality or price competition, 50 to $60 \%$ of HS 6-digit codes exports of large European nations can be classified as 'quality goods', while only 30 to $40 \%$ of US and Japanese exports fall into this category.

We believe that the difference may lie in pervasive trade in parts and components stemming from US and Japanese companies' offshoring strategies that means nearby customers (the offshored factories) are a different type of buyers than the far away customers (arm's length purchasers).

2) For commodity exporters like Canada and Australia, the fraction of quality goods is much lower, only $15-25 \%$. The share of quality goods in China's exports also fall in this range.

We believe that this fits in with our priories that nations with a comparative advantage in raw materials should systematically see a lower incidence of quality-type goods in their export mix.

\section{Literature}

One of the pioneering articles on the empirical front to use price as a proxy for quality is Schott (2004). It has documented a large difference in product prices within the most disaggregated level of product classification. Schott (2008) shows that the US consumers pay less for "Made in China" than for “Made in OECD” for similar goods. Fontagné, Gaulier, and Zignago (2008), analysing unit prices of HS 6-digit products of 200 countries, finds that the developed countries' products are not directly competing with the developing countries' products. Especially, because of their products' superior quality, EU countries have less direct competition with the developing countries than Japan or the US does. These findings have important policy relevance. It suggests that developed countries can maintain their competitiveness by climbing up the quality ladders within the existing industries rather than moving to a new industry. But which goods are quality goods? We, consumers, also know that some goods are not competing in qualities but in prices. Commodity goods and raw materials are mostly competing in prices. Thus, it is interesting and useful for policy purposes to sort out products by the degree of quality or price competition.

\section{Plan of paper}

Section 2 briefly reviews the theory that structures our empirical exercise. Section 3 explains the data, estimation equation and results. The final section concludes.

\section{THEORETICAL FRAMEWORK}

To structure our empirical analysis, we briefly summarize the price competition and quality competition versions of the heterogeneous firms trade model, highlighting two simple empirically testable predictions of these models.

The classic HFT model (Melitz 2003) can be thought of as the Dixit-Stiglitz monopolistic competition trade model where firms have randomly drawn marginal cost functions and face iceberg trade costs as well as a fixed cost of establishing a 'beachhead' in each market. As usual, the Dixit-Stiglitz structure links the value of sales directly to operating profits, so the beachhead cost means that only sufficiently competitive firms export. Moreover, distance-linked iceberg trade costs imply that a firm's competitiveness is diminished in more distant markets, so export status displays a distance-marginal cost gradient. The threshold degree of competitiveness necessary to sell in markets rises with the market's distance, so average competitiveness of firms servicing a particular market rises with distance.

The HFT and QHFT models differ only in their determinants of competitiveness. In HFT, price is the sole basis of competition, i.e. market entry thresholds can be written in terms of a maximum price. In QHFT, competitiveness depends upon quality-adjusted price, so market-entry thresholds are defined in terms of quality-adjusted price. In the standard version of the model, the lower quality-adjusted prices (unobserved) are associated with higher unadjusted (observed) prices. In other words, firms only export the most expensive goods to the most distant markets. 
The BH test of this prediction found that the QHFT provided a better explanation of the US export data for 2005. That finding, however, pools across all US exports, thus implicitly assuming that all US exports are marked either by quality competition or by price competition.

In this paper, we explore the hypothesis that some goods may fit HFT predictions while others fit the QHFT predictions. The hope is that we can identify a set of products which are - for a number of major exporting nations - characterised by either HFT or QHFT.

\section{DATA, EMPIRICAL MODEL AND RESULTS}

Taking the distance-price prediction to the data requires some care in handling the theoretical predictions. Suppose we had the true product-level data, i.e. data on the prices and sales by particular firms of particular products in particular destination markets. If the baseline model is true, Dixit-Stiglitz mark-up pricing would imply that the producer price, i.e. FOB price, for each variety would be insensitive to distance. The point is that the distance-price-gradient prediction stems from product/firm selection, not from firms' pricing behaviour.

However, if we work with publicly available trade data, where the finest disaggregation available for all nations is HS 6-digit for all nations (HS 9-digit or HS 10-digit for some nations) then distance will have a selection effect. We should find that the average export price rises (QHFT) or falls (HFT) due to an unobserved shift in the bilateral composition of varieties/firms.

For example HS6 category 854449 comprises “Other electric conductors for a voltage less than or equal to 80 volts”. Inside this category will be some high priced varieties and some low priced varieties (they coexist in both models due to product differentiation). The empirical lever comes from the way the nation-specific price mix changes with distance of the market. If QHFT is correct, Germany's HS 854449 export basket to France will have more low priced varieties than its export basket to the US. Empirically, this will show up as a lower unit value index for Germany's HS 854449 exports to France. If the HFT model is correct, we should observe the opposite.

We conduct the analysis at the HS 6-digit level because this is the most disaggregated internationally harmonised classification code. Thus if our classification is to prove useful for a broad range of nations, it must be at the HS 6-digit level. Below, we report some sensitivity analysis at the HS 9-digit level for Japan.

\subsection{Empirical model and results}

The empirical model we employ is akin to $\mathrm{BH}$. The main differences lie in our use of log-linear distance (instead of distance bands) and our panel dimension.

BH uses a panel for US exports of different products to different destinations but for a single year. Our panel data looks at a given origin nation's exports of a given HS6 product to all the destination countries over a ten years period (1997-2006). For example, as is shown below, 4,845 HS 6-digit lines have at least 20 observations for the whole period. We run 4,845 regressions for the US. We do the same for the other 8 exporters. In total, we estimate approximately 40,000 regressions.

The regression equation is:

$$
p_{t, d}=\beta_{0}+\beta_{1} \log \left(D I S T_{d}\right)+\beta_{2} \log \left(G D P_{t, d}\right)+\beta_{3} \log \left(G D P C A P_{t, d}\right)+\tilde{\beta}_{4} D+\varepsilon_{t, d}
$$

where $p_{t, d}$ is the log of the FOB unit value index to destination country $\mathrm{d}$ at time $\mathrm{t}, \mathrm{DIST}_{d}$ is the bilateral distance from the exporter under study and destination country d, and $G D P_{t, d}$ is the destination-country GDP at time $t$; GDPCAP $P_{t, d}$ is the corresponding GDP per capita. $D$ is a vector of year dummies. $\varepsilon_{t, d}$ is an iid error. 


\subsection{Data}

The export data we use is for 9 exporters (the world's top 8 exporters plus Australia) for 1997 to 2006. These are taken from the UN COMTRADE database. The distance data are from CEPII; the GDP and population data are from the World Development Indicators of the World Bank.

For the nine exporting nations we work with, Table 1 shows the world export rank and the number of HS 6-digit lines with at least 20 observations.

Table 1: Global export rank and numbers exported HS6 lines

\begin{tabular}{lccccccccc}
\hline \hline & US & Germany & Japan & China & France & UK & Italy & Canada & Australia \\
\cline { 2 - 9 } Rank & 1 & 2 & 3 & 4 & 5 & 6 & 7 & 8 & 26 \\
Lines & 4,845 & 4,550 & 4,150 & 4,557 & 4,674 & 4,751 & 4,664 & 3,465 & 3,942 \\
\hline \hline
\end{tabular}

Source: UN COMTRADE, Author's calculation.

\subsection{Results}

Table 2 summarises the results. ${ }^{3}$ The first column shows the number of HS6 products for which the distance coefficient is statistically significant at least at the $5 \%$ level. The second and third columns show the breakdown between the lines with positive and negative coefficients on distance, respectively. The first three lines show the results for the US, Germany and Japan. Consider the US numbers.

Out of the US's 4,845 HS 6-digit products, 1,957 products have statistically significant distance coefficients with 1,667 of these being positive. This suggests that about $34 \%$ of US HS6 exports are 'quality goods', about $6 \%$ are 'price goods'. The remainder, almost $60 \%$, cannot be classified, perhaps because the statistical groupings bundle together some price and some quality products.

The results for Japan are broadly consistent with those for the US, with 38\% of the HS6 lines displaying positive distance coefficients (suggesting quality competition) and $9 \%$ displaying negative coefficients.

Findings for the four large EU exporters, Germany, France, Britain and Italy, reveal a much higher share of quality goods. About $50 \%$ of German, French and British exports are classified as quality goods, while the figure for Italy is almost $60 \%$. We also note that the share of unclassifiable lines is much lower for these nations, with the share range from $33 \%$ for Italy to $48 \%$ for Britain, while France and Germany both close to $40 \%$.

An informal test is given by contrasting these results for highly industrial nations with nations who are known to be more dependent on commodity exports where we expect price to matter more than quality.

Australia and Canada are the nations we chose as they are both large exporters, heavily reliant on primary good exports and have excellent data. For these two nations the share of quality goods is only 15\% (Canada) and 27\% (Australia). The share of price goods is 7\% for Canada, and 5\% for Australia.

China presents an interesting case. Its exports are dominated by industrial goods, but it is widely perceived to be an export of varieties where low prices are the key to their success. What we find is that about $21 \%$ of its exports are quality-goods by our measure and $17 \%$ of its exports are price goods.

\footnotetext{
${ }^{3}$ See the separate file for the whole list of quality and price competition goods by country.
} 
Table 2: Numbers of quality-competition and price-competition goods

\begin{tabular}{lccc}
\hline \hline & $\begin{array}{c}\text { Number HS6 lines where } \\
\text { distance is significant at } \\
5 \%\end{array}$ & $\begin{array}{c}\text { Number with positive } \\
\text { coefficient } \\
\text { (quality competition) }\end{array}$ & $\begin{array}{c}\text { Number with negative } \\
\text { coefficient } \\
\text { (price competition) }\end{array}$ \\
\hline USA & 1,957 & 1,667 & 290 \\
Germany & 2,531 & 2,251 & 280 \\
Japan & 1,947 & 1,590 & 357 \\
Overlap (J, D, US) & 510 & 322 & 1 \\
\cline { 2 - 4 } France & 2,749 & 2,519 & 230 \\
UK & 2,464 & 2,232 & 142 \\
Italy & 3,136 & 2,994 & 244 \\
Canada & 754 & 510 & 180 \\
Australia & 1,255 & 1,075 & 776 \\
China & 1,722 & 946 & 232 \\
\hline \hline
\end{tabular}

Source: UN COMTRADE, Authors' calculation.

\subsection{Overall among US, German and Japanese quality goods}

The next question is whether these goods classified at HS 6-digit level are common to the countries in study. The fourth row of Table 2 shows the number of HS 6-digit lines that overlap among the US, Japan and Germany, i.e. the number of products which show statistically significant coefficient estimates of the same sign for the distance variable for all the three countries.

Out of 3,905 HS 6-digit product lines which were common for all the three countries, 510 show statistically significant coefficients for all the three countries. Out of the 510 product lines, 322 show statistically significant positive coefficient estimates for all the three countries. We would like to suggest that these HS codes could be considered as marked by 'quality goods'. The 322 figure represents just $8 \%$ of the 3,905 HS 6-digit product lines exported (about 10\% in terms of export value).

Only one HS 6-digit code has statistically significant negative coefficient estimate for all the three countries.

There are 157 products that show two positive signs and one negative sign, so maybe we could call these quasi-quality competition goods. 30 products show one positive sign and two negative signs. The proportion of quality and quasi-quality competition goods is much higher than price and quasi-price competition goods. The rather small proportion of the overlap of product codes across the three countries implies that the product mixture in terms of quality/price competition for a particular HS 6-digit code is different across countries.

\subsection{More detailed disaggregation}

Fact that less than one out of ten lines can be unanimously classified as quality or price goods suggests that there may be a great deal of heterogeneity (across exporters) among the basket of goods included in each HS6 category. 
To investigate the hypothesis, we compare the analyses at HS6 results with estimates on HS 9-digit data for Japan. Specifically we reproduce the above procedure for all the HS9 lines within given HS6 codes. Since the purpose here is a simple check, not an exhaustive analysis, we have conducted an analysis using a random sample from HS codes.

Japan has approximately 5,000 lines at the HS6 level with roughly 9,100 lines at the HS9 level. Some HS6 codes have only a single HS9 code, rendering our test invalid so we discard all such HS6 codes and then take a $1 \%$ random sample of the remaining HS6 codes. For these randomly sampled HS6 codes, we have taken the export data at the HS9 level. The regression is run for each HS 9-digit code. The test will come from comparing the distance coefficient estimates for the HS6 aggregate with the more disaggregate estimates for the HS9 codes encompassed by the HS6 code.

Table 3 summarises the results. The left panel shows that HS6 result, with the first column displaying the HS6 code, the second the distance coefficient and the third the p-value. The fourth column summarise the finding by putting a + or - where the distance coefficient is positive or negative at the $5 \%$ level respectively. The right panel shows similar statistics for the HS9 codes that make up the HS6 code listed. The final column summarises the match between the two as a half-match $(\mathrm{H})$, a full-match (F) or more-than-half-match (MF). $\mathrm{N}$ indicates no-match.

If HS9 heterogeneity is a key source of the low number of goods that can be clearly classified as quality or price goods, then we should see a stark mismatch between the results indicated by the HS9 data and the more aggregated HS6 data, i.e. many " $N$ " in the final column.

Out of the total 16 HS 6-digit codes we checked, 7 have full fit and 3 have more than a half fit. Only 3 have no match. Closer examination of the no-match cases is revealing. In two of the cases (520544 and 611120), the distance coefficient is positive and significant for the data pooled at the HS6 level, but none of the underlying HS9 coefficients are significant. We note however that the HS9 coefficients are positive. This suggests that the lack of variation in the HS9 export destinations may account for the lack of statistical significance.

The remaining case of no match (901890) is very instructive. Here we see that most of the HS9 coefficients are positive, but one is negative. The aggregate HS6 coefficient is estimated to be negative but not significantly different from zero. This case suggests that the HS6 classification is inappropriate for our purposes in that it pools price and quality goods. If this sort of result were widespread, then it would cast doubt on our HS6 results, but the fact that it occurs in only one of the 16 cases provides some assurance that our HS6 estimates are yielding useful results.

While further testing is required, using for example US HS10 and EU HS8 data, our exploratory investigation suggests that analysis at HS6 level provides a reasonably good indication of the underlying situation. It is particularly important to note that in no case did the HS6 result indicate that the line was a quality or price good when the HS9 data indicated otherwise.

Our finding does not resolve the issue of the low number of clearly classifiable HS6 codes. We cannot say whether there is something wrong with our empirical framing of the question, or whether the problem lies in heterogeneity (by exporting country) of basket of goods in the HS9 codes. 
Table 3: HS6 vs HS9 estimates

\begin{tabular}{|c|c|c|c|c|c|c|c|c|}
\hline $\begin{array}{l}\text { HS6 } \\
\text { code }\end{array}$ & $\begin{array}{c}\text { Distance } \\
\text { coefficient }\end{array}$ & $\mathrm{p}$ & $\begin{array}{c}\text { Sign of significant } \\
\text { coefficients }\end{array}$ & HS9 code & $\begin{array}{c}\text { Distance } \\
\text { coefficient }\end{array}$ & $\mathrm{p}$ & $\begin{array}{c}\text { Sign of the coefficient } \\
\text { estimate }\end{array}$ & Fit \\
\hline \multirow[t]{2}{*}{030791} & \multirow[t]{2}{*}{0.79} & \multirow[t]{2}{*}{0.00} & \multirow[t]{2}{*}{+} & 030791100 & 0.54 & 0.06 & & \multirow{2}{*}{$\mathrm{H}$} \\
\hline & & & & 030791100 & 0.81 & 0.00 & + & \\
\hline \multirow[t]{2}{*}{370252} & \multirow[t]{2}{*}{0.23} & \multirow[t]{2}{*}{0.00} & \multirow[t]{2}{*}{+} & 370252000 & 0.20 & 0.00 & + & \multirow{2}{*}{$\mathrm{F}$} \\
\hline & & & & 370252100 & 0.26 & 0.00 & + & \\
\hline \multirow[t]{2}{*}{390290} & \multirow[t]{2}{*}{-0.03} & \multirow[t]{2}{*}{0.73} & & 390290100 & 0.11 & 0.13 & & \multirow{2}{*}{$\mathrm{F}$} \\
\hline & & & & 390290900 & 0.15 & 0.20 & & \\
\hline \multirow[t]{4}{*}{500720} & \multirow[t]{4}{*}{0.11} & \multirow[t]{4}{*}{0.12} & & 500720110 & 0.28 & 0.05 & & \multirow{4}{*}{$\mathrm{F}$} \\
\hline & & & & 500720120 & 0.09 & 0.13 & & \\
\hline & & & & 500720190 & 0.15 & 0.07 & & \\
\hline & & & & 500720200 & 0.19 & 0.20 & & \\
\hline \multirow[t]{2}{*}{520544} & \multirow[t]{2}{*}{0.21} & 0.01 & + & 520544100 & 0.04 & 0.77 & & $\mathrm{~N}$ \\
\hline & & & & 520544900 & 0.15 & 0.13 & & N \\
\hline 520831 & -0.24 & 0.01 & - & 520831100 & -0.32 & 0.01 & - & \\
\hline & & & & 520831200 & -0.05 & 0.62 & & $\mathrm{MH}$ \\
\hline & & & & 520831300 & -0.15 & 0.05 & - & IVIH \\
\hline & & & & 520831900 & -0.21 & 0.04 & - & \\
\hline 540744 & -0.17 & 0.10 & & 540744100 & -0.18 & 0.30 & & $F$ \\
\hline & & & & 540744900 & -0.14 & 0.17 & & $\mathrm{~F}$ \\
\hline 610690 & 0.33 & 0.00 & + & 610690100 & 0.51 & 0.00 & + & $\mathrm{H}$ \\
\hline & & & & 610690900 & 0.17 & 0.51 & & П \\
\hline 610990 & 0.40 & 0.00 & + & 610990110 & 0.67 & 0.00 & + & \\
\hline & & & & 610990120 & 0.51 & 0.00 & + & \\
\hline & & & & 610990190 & 0.34 & 0.00 & + & $\mathrm{MH}$ \\
\hline & & & & 610990910 & 0.23 & 0.10 & & \\
\hline & & & & 610990990 & 0.46 & 0.02 & + & \\
\hline 611120 & 0.35 & 0.00 & + & 611120295 & 0.02 & 0.89 & & \\
\hline & & & & 611120300 & 0.12 & 0.49 & & $\mathrm{~N}$ \\
\hline & & & & 611120900 & 0.01 & 0.95 & & \\
\hline 611610 & -0.25 & 0.00 & - & 611610000 & -0.36 & 0.02 & - & $\mathrm{H}$ \\
\hline & & & & 611610500 & -0.14 & 0.14 & & H \\
\hline 710692 & 0.94 & 0.00 & + & 710692100 & 0.82 & 0.00 & + & $F$ \\
\hline & & & & 710692900 & 0.43 & 0.00 & + & $\mathrm{F}$ \\
\hline 841430 & 0.32 & 0.00 & + & 841430100 & 0.29 & 0.00 & + & $F$ \\
\hline & & & & 841430900 & 0.24 & 0.00 & + & $\mathrm{F}$ \\
\hline 845630 & 0.20 & 0.00 & + & 845630110 & 0.18 & 0.00 & + & \\
\hline & & & & 845630190 & 0.23 & 0.00 & + & $\mathrm{F}$ \\
\hline & & & & 845630900 & 0.80 & 0.00 & + & \\
\hline 854449 & 0.10 & 0.29 & & 854449100 & 0.17 & 0.62 & & \\
\hline & & & & 854449110 & 0.58 & 0.00 & + & \\
\hline & & & & 854449190 & 0.70 & 0.00 & + & $\mathrm{MH}$ \\
\hline & & & & 854449910 & 0.02 & 0.85 & & \\
\hline & & & & 854449990 & -0.05 & 0.71 & & \\
\hline 901890 & -0.06 & 0.32 & & 901890110 & 0.12 & 0.00 & + & \\
\hline & & & & 901890190 & 0.20 & 0.00 & + & \\
\hline & & & & 901890200 & 0.59 & 0.00 & + & \\
\hline & & & & 901890311 & 0.05 & 0.61 & & $\mathrm{~N}$ \\
\hline & & & & 901890319 & 0.33 & 0.00 & + & \\
\hline & & & & 901890390 & -0.31 & 0.00 & - & \\
\hline & & & & 901890900 & 0.12 & 0.25 & & \\
\hline
\end{tabular}




\section{CONCLUSION}

This seeks to classify HS6 digit products as being characterised either by price-competition or by quality-competition goods as suggested by the HFT and QHFT models. We find that about 8\% of HS6 codes can be thus classified in the sense that results for the US, Germany and Japan all coincided.

Of the goods that can be clearly classified, we find that the major EU countries are leading the quality competition race with 50 to $60 \%$ of their exports being goods in which quality seems to matter in the sense that the goods that get sold to the most distant markets are the most expensive ones. For Japan and the US the figures are lower at 38 and $34 \%$ respectively. Canada, Australia and China have much lower proportions of quality-competition goods.

To check for problems with aggregation, we analyse Japan's export data at the HS 9-digit level and its aggregation into the HS6 scheme. We find few difference in the inferences that come from analysis at the HS9 versus HS6 level.

\section{REFERENCES}

Baldwin, Richard and Harridan, James (2007). "Zeros, Quality and Space: Trade Theory and Trade Evidence " CEPR Discussion Paper No. 6368.

Baldwin, Richard (1988). "Hysteresis in Import Prices: The Beachhead Effect," American Economic Review, American Economic Association, vol. 78(4), pages 773-85, September.

Fontagné, Gaulier, and Zignago. (2008) "Specialization across varieties and North-South competition", Economic Policy, January 2008, 53-91.

Krugman, P. (1980) "Scale Economies, Product Differentiation and the Pattern of Trade” American Economic Review, 70, 950-959.

Melitz, Marc J. (2003), .The Impact of Trade on Intra-Industry Reallocations and Aggregate Industry Productivity,. Econometrica, 71:6, pp. 1695-1725.

Schott, Peter. (2008) "The relative sophistication of Chinese exports", Economic Policy, January 2008, 7-49. 